\title{
Integralidade nas práticas educativas no cenário escolar: Revisão integrativa da
}

\section{literatura brasileira}

Integrality in the educational practices in the scholar scenery: Integrative revision in the brazilian literature

Integralidad en las prácticas educativas en el ámbito escolar: Revisión integradora de la literatura brasileña

\section{Resumo}

Objetivo: analisar as produções científicas acerca da integralidade nas práticas educativas no contexto escolar. Método: revisão integrativa da literatura, realizada nas bases de dados PUBMED, LILACS, BVS e SCIELO, por meio de cruzamento dos descritores: "ação intersetorial" e "saúde na escola". Selecionaram-se sete publicações, das quais emergiram duas categorias temáticas: 1. estratégias para práticas educativas no cenário escolar; 2. desafios e limites das práticas educativas no cenário escolar. Resultados: As ações executadas pelos trabalhadores de saúde são práticas educativas tradicionais e verticalizadas no ambiente escolar. Esses profissionais apresentaram dificuldades e fragilidades na formação para desenvolver práticas educativas mais dialógicas e participativas que possibilitem o processo na formação de cidadãos reflexivos e críticos em uma perpectiva ampliada de promoção de saúde. Conclusão: a integralidade é uma estratégia inovadora no campo da saúde e educação, ainda em construção. Apontase a criação de agenda única, a fim de potencializar processos educativos permanentes para promover práticas educativas pautadas pela integralidade nas políticas públicas.

Palavras-chave: Promoção da saúde; Colaboração intersetorial; Saúde escolar; Equipe de assistência ao paciente.

\begin{abstract}
Objective: to analyses scientific productions about integrality in the educative practices in the scholar context. Method: integrative review of the literature realized in the bases of data PUBMED, LILACS, BVS and SCIELO through of descriptors crossings: "intersectorial action" and "school health". Seven publications were chosen, of these increase two thematic categories: skills to educative practices in the scholar scenery and challenges and limits of them. Results: The analyses of studies showed that actions executed by health professionals are traditional educative practices and introduced in the scholar enenvironment. These professionals have difficulties and fragilities in the formation to develop more dialogical and participative educative practices that get possibility to the process in the formation of reflexive and critical citizens in a perspective applied of health promotion. Conclusion: to raise to power educative processes remain what let the ability to professionals to exercise of educative practice based for integrality in the public politics.
\end{abstract}

Keywords: Health promotion; Intersectoral collaboration; Scholar health; Patient care team.

\section{Resumen}

Objetivo: analizar las producciones científicas sobre integralidad en las prácticas educativas en el contexto escolar. Método: revisión integrativa de la literatura, en las bases de datos PUBMED, LILACS, BVS y SCIELO, mediante el cruce de los descriptores: "acción intersectorial" y "salud en la escuela". Se seleccionaron siete publicaciones, de las cuales surgieron dos categorías temáticas: estrategias para las prácticas educativas en el ámbito escolar y desafíos y límites de las prácticas educativas en el ámbito escolar. Resultados: Las acciones realizadas por los trabajadores de la salud son prácticas educativas tradicionales y verticalizadas en el ámbito escolar. Estos profesionales presentaron dificultades y debilidades en la formación para desarrollar prácticas educativas más dialógicas y participativas que posibiliten el proceso en la formación de ciudadanos reflexivos y críticos, en la perspectiva ampliada de promoción de la salud. Conclusión: la integralidad es una estrategia innovadora en el campo de la salud y la educación, aún en 
construcción. El objetivo es crear una agenda única. Fortalecer los procesos educativos permanentes para promover prácticas educativas guiadas por la integralidad en las políticas públicas.

Palabras clave: Promoción de la salud; Colaboración intersectorial; Salud escolar; Grupo de atención al paciente.

\section{Introdução}

A palavra integralidade encontra-se no discurso propagado por organismos internacionais ligado ao ideário da Atenção Primária à Saúde (APS) e de promoção de saúde (Fracolli, Zoboli, Granja \& Ermel, 2011). No entanto, esse termo é dotado de diversos sentidos, expresso no contexto de luta do Movimento Sanitário brasileiro. No campo da saúde, a integralidade tem compressões que podem ser analisadas em três dimensões: na formulação de políticas de saúde, nas organizações dos serviços de saúde e nas práticas de saúde (Mattos, 2009).

Para Pinheiro (2008) a integralidade é um eixo prioritário da política de saúde como meio de concretizar as ações na intenção de compreender a operacionalização do sistema a partir dos processos organizativos, da implantação de inovações no cotidiano nos serviços e nas relações entre os níveis de gestão do Sistema Único de Saúde (SUS).

Compreende-se a integralidade como um dos pilares constitucionais do SUS, que se fundamenta na garantia de assistência em todos os níveis de densidade tecnológica e articulação entre promoção, proteção, prevenção, atenção e reabilitação em todos os níveis de proteção.

Nesse contexto, dentre os diversos espaços dos serviços de saúde, destaca-se o de atenção básica enquanto contexto privilegiado para desenvolvimento de práticas educativas em saúde, caracterizados pela maior proximidade com usuários e a ênfase em ações preventivas e promoção da saúde. Assim, os serviços de atenção básica precisam apropriar-se de tecnologia de alta complexidade que envolve conhecimentos, habilidades e técnicas, dentre as quais é possível reconhecer a educação em saúde (Mendes, 1996).

Para operacionalizar as práticas em educação e saúde, nas últimas décadas, o Ministério da Saúde e Ministério da Educação instituíram o Programa Saúde na Escola (PSE), pelo Decreto Presidencial nº 6.286/2007, com objetivo de construir políticas intersetoriais no campo da saúde e da educação para melhoria da qualidade de vida dos educandos.

Dessa forma, trata-se a saúde e a educação integrais como parte de uma formação ampla para cidadania, a fim de enfrentar as necessidades dos escolares no campo da saúde. Assim, partir desta perspectiva, identifica-se a escola como espaço de relações, cuja dinâmica do ambiente é ideal para o desenvolvimento do pensamento crítico e político, mediante práticas de promoção de saúde.

Nota-se que as práticas educativas realizadas por profissionais de saúde no cotidiano da assistência têm enfatizado a transmissão de informações e o estímulo à mudança de comportamento individual em relação ao modo de cuidar em saúde. No entanto, tais práticas têm se mostrado pouco efetivas para atender às necessidades do cuidado à saúde dos escolares e dos respectivos familiares (Magalhães, 2015).

Outro aspecto que merece destaque é que os profissionais de saúde demonstram dificuldade e fragilidade na formação para desenvolver metodologias mais dialógicas e participativas. Assim, a problematização da integralidade das práticas educativas no cenário escolar constitui-se como ponto de partida para aprendizagem significativa, na construção de novos conhecimentos pautados na necessidade de refletir e fundamentar, cientificamente, sobre as formas de intervir na realidade (Kantor, 2010; $\underline{\text { Hermann, }}$ Head, Black \& $\underline{\text { Singleton, 2016) }}$

Apesar do avanço da literatura nessa direção, observa-se que a formação dos profissionais da saúde ainda está pautada no modelo biomédico, fragmentado e especializado, o que dificulta a compreensão dos determinantes e a intervenção sobre os condicionantes do processo saúde-doença. Além da fragilidade do conhecimento, cria-se obstáculos para a construção da integralidade da assistência (Feuerwerker, 1998). 
Nessa perspectiva, destaca-se a necessidade de promover aproximação entre as instituições de educação e os serviços de saúde, para estimular novas abordagens em educação em saúde com base no pensamento crítico e na aprendizagem significativa (Lima, Reibnitz, Prado \& Kloh, 2013; Dias, Ribeiro, Silva, Vasconcelos \& Machado, 2016; Westin, Sundler \& Berglund, 2015).

Com isso, emergiu-se a seguinte inquietação: “Como acontecem as práticas educativas entre a saúde e educação? Essa temática mostra-se relevante por encontrar-se ancorada na necessidade de compreender como os profissionais constroem suas práticas educativas em saúde, em uma proposta de educação crítica e reflexiva, a partir de uma base teórica que possa sustentar a formação continuada e qualificar a ação, a fim de atender às demandas dos usuários.

Face ao exposto, o estudo objetivou analisar as produções científicas acerca da integralidade nas práticas educativas no contexto escolar.

\section{Metodologia}

Trata-se de uma revisão integrativa da literatura, produzida com base em artigos selecionados aos seguintes eixos temáticos: integralidade das práticas educativas no cenário escolar e intersetorialidade no campo da saúde e educação, no período de abril a maio em 2017. As buscas foram realizadas nas bases de dados Pubmed Central, LILACS, BVS e SCIELO, optou-se por essas bases de dados por entender que atingem a literatura publicadas nos países da América Latina e Caribe, utilizando-se dos seguintes termos indexados nos Descritores em Ciências da Saúde Coletiva (DeCSC), juntamente com os operadores booleanos "AND" e "OR": "ação intersetorial" AND e OR "saúde na escola".

A primeira busca foi realizada nas bases de dados Pubmed Central (PMC), LILACS, BVS e SCIELO, em que se encontraram 102 artigos. Utilizaram-se dos filtros, com a finalidade de obedecer aos critérios de inclusão: texto completo; assunto principal: integralidade nas práticas educativas no cenário escolar e a intersetorialidade; limites: crianças e adolescentes; idiomas: inglês e português; tipo de documento: artigos, vindo a retornar com 61 artigos. A segunda busca foi realizada na base de dados LILACS que retornou com 32 artigos. Com a utilização dos filtros: idiomas português e inglês; publicados nos últimos cinco anos. A terceira busca foi realizada na base de dados BVS, sendo encontrados oito artigos, com a utilização dos mesmos filtros. Por última, a base de dados SCIELO, com apenas um artigo. Dos sete manuscritos publicados, seis estavam em língua portuguesa e um em inglês, todos autores eram brasileiros, em formato de artigos originais, com disponibilidade na íntegra on-line e gratuitos.

Os artigos encontrados foram comparados, com o propósito de encontrar duplicidade que apareceram nos idiomas selecionados e nas diferentes bases de dados. Na PUBMED, localizaram-se 61 estudos, entretanto, dois encontravam-se indexados na MEDLINE, concomitantemente. Em seguida, realizaram-se leituras dos títulos e resumos, excluindo os que não disponibilizavam o texto completo; os que incluíam a temática integralidade das práticas educativas no espaço escolar e a intersetorialidade entre a saúde e educação, que não apresentaram conteúdo relevante para temática pesquisada; que incluíam outros grupos, como agentes de endemias, agentes comunitários de saúde e artigos de revisão, obedecendo-se aos critérios de exclusão. Assim, por entendimento dos pesquisadores e em obediência aos critérios de inclusão e exclusão, selecionaram sete artigos que passaram a compor a amostra.

Para construção desta revisão integrativa, seguiram-se rigorosamente as etapas a seguir, demonstradas na Figura 1. 
Figura 1. Etapas de busca nas bases de dados.

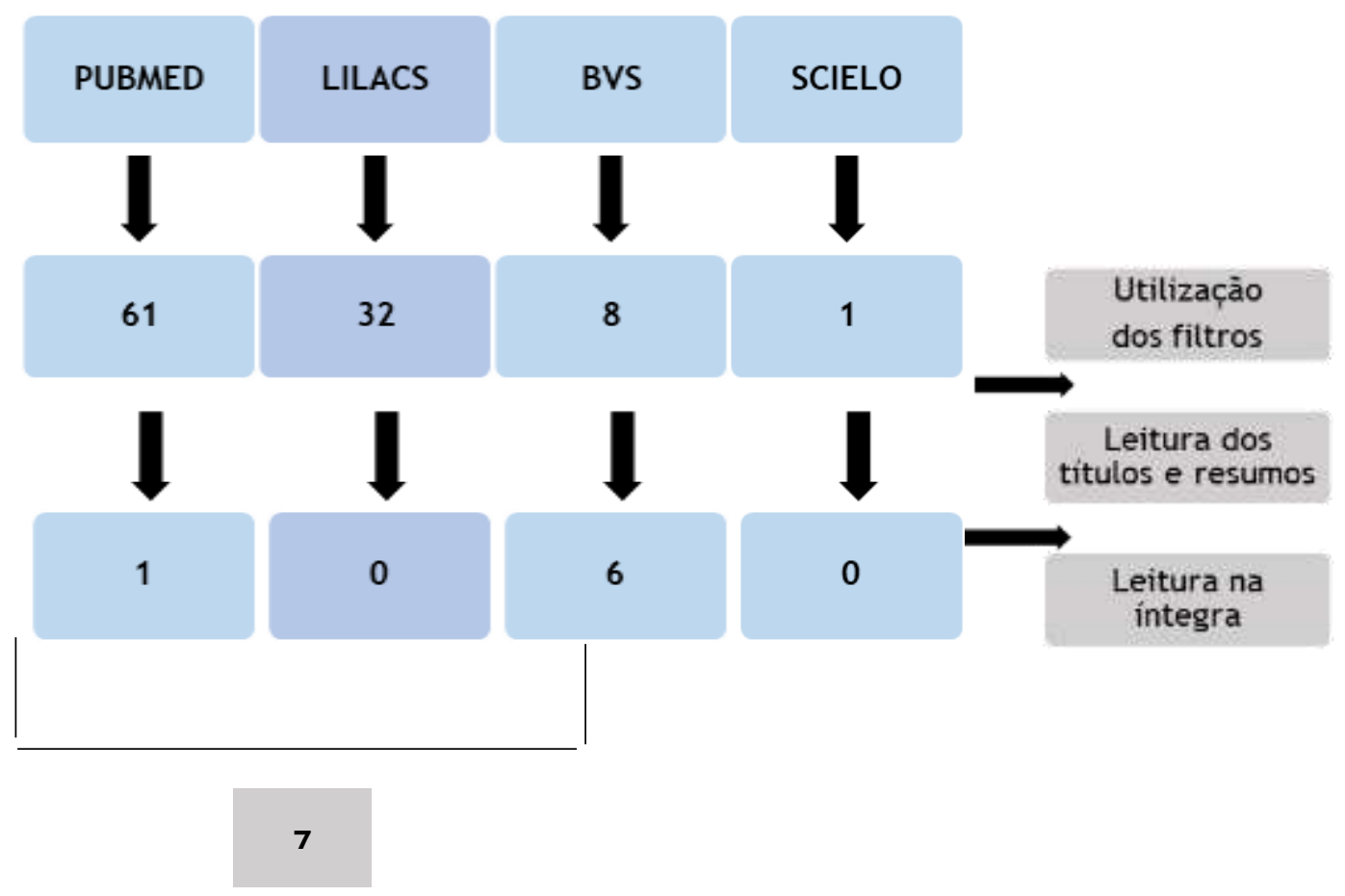

Fonte: Autores (2021).

\section{Resultados}

Na presente revisão integrativa de literatura foram selecionados sete artigos, identificou-se o seguinte delineamento de pesquisa: cinco(71,4\%) artigos utilizaram abordagem qualitativa, um $(14,3 \%)$ quantitativo e um $(14,3 \%)$ misto, enquanto que cinco $(71,4 \%)$ estudos são descritivos, um(14,3\%) exploratório e apenas um (14,3\%) do tipo exploratório-descritivo.

Esses estudos são do tipo: pesquisa-ação, com maior significância, e um estudo de caso. A pesquisa-ação consiste em uma relação interacional entre o pesquisador e os pesquisados (Thiollent, 2011).

Os estudos foram realizados no Brasil, em quatro municípios de porte médio, nas regiões Sudeste (Minas Gerais, São Paulo e Rio de Janeiro), que correspondem universo de 57,1\%, enquanto que três em município de pequeno porte, 42,9\% na região Nordeste (Ceará e Pernambuco).

Os participantes desses estudos foram os seguintes integrantes: quatro $(57,1 \%)$ formado por grupos específicos, composto por gestores, coordenadores, profissionais de saúde, professores, agentes comunitários de saúde, auxiliares de serviços, alunos e mães, dois $(28,6 \%)$ por adolescentes e um (14,3\%) formado por crianças e adolescentes.

Para descrição e registro dos dados, utilizou-se a observação estruturada, assim distribuída: quatro $(57,1 \%)$ a entrevista com maior predominância, dois $(28,6 \%)$ questionário, e por último, um $(14, \%)$ diário de campo e observação participante.

A ênfase dos estudos esteve dirigida, em maioria, a processos educativos: ações em educação e saúde (85,5\%), seguida de ações intersetoriais na prevenção de acidentes e da violência urbana $(28,4 \%)$. Dado que despertou atenção referiu-se às intervenções realizadas de forma compartilhada e cooperativas em $71,6 \%$ dos estudos, enquanto que $28,4 \%$ das ações foram fragmentadas, pontuais e pouco efetivas na promoção da saúde no ambiente escolar.

$\mathrm{Na}$ classificação dos estudos, quanto ao contexto em que se realizaram, a maior parte foi em ambiente escolar, ao concentrar seis estudos $(85,7 \%)$ em área de vulnerabilidade social, com maior incidência de violência, e em domicílio e comunidade escolar, apenas um estudo (14,3\%). 
A análise dos artigos selecionados, interligou-se a análise teórica e observação empírica, com enfoque nos aspectos essenciais de definições e mensurações dos fenômenos em análise, assim distribuídos: quatro $(57,1 \%)$ análise de conteúdo (Bardin, 2011): um (14,3\%) documental, um (14,3\%) temática e um(14,3\%) triangulação de dados, respectivamente, com Método do Círculo de Cultura (Freire, 2010).

O Círculo de Cultura apresenta pressupostos teóricos e metodológicos para ser adotado como um método que mobiliza e instiga os participantes da saúde e educação a pensar sobre a realidade dentro de uma concepção de reflexão-ação.

Para Freire (2010), o processo dialético fomenta o espaço de troca e aprendizagem das práticas educativas em saúde, por meio de práticas participavas que ganham vida nas relaçães entre os trabalhadores do campo da saúde e educação, como estratégico de formação e intervenção educativa que valorize a experiência do grupo e promova sua participação na construção do conhecimento coletivo.

Esse modelo de educação em saúde permite novas alternativas metodológicas, um dos métodos mais utilizados no Círculo de Cultura é o espaço em que dialogicamente se ensina e se aprende que não há espaço para transferência de conhecimento, mas a construção de saber do educando, com hipóteses de leitura de mundo (Freire, 2002).

O mesmo autor acrescenta que é imprescindível, o exercício de uma prática educativa crítica constitui uma forma de intervenção no mundo, comprometida com o princípio de democracia que rejeita qualquer forma de discriminação, dominação e integra uma atitude de inovação e renovação, na crença de que é possível mudar (Freire, 2005).

A análise das evidências permitiu identificar duas categorias: estratégias para integralidade nas práticas educativas no cenário escolar e desafios e limitações para integralidade nas práticas educativas no cenário escolar (Tabelas 1 e 2).

Tabela 1. Distribuição dos artigos incluídos na revisão integrativa, de acordo com autoria, ano de publicação, periódicos e objetivos.

\begin{tabular}{|c|c|c|}
\hline Artigos & Periódicos & Objetivos \\
\hline 1 & Caderno de Saúde Pública & $\begin{array}{l}\text { Analisar a implementação de ações intersetoriais previstas nos programas Bolsa Família, } \\
\text { Saúde da Família e Saúde na Escola, em Manguinhos, zona norte do Município do Rio de } \\
\text { Janeiro. }\end{array}$ \\
\hline 2 & Ciência e Saúde Coletiva & Colaborar com ação intersetorial no projeto saúde e prevenção na escola. \\
\hline 3 & $\begin{array}{l}\text { Interface } \\
\text { Comunicação Saúde e } \\
\text { Educação }\end{array}$ & $\begin{array}{l}\text { Descrever e analisar o processo de } \\
\text { enfrentamento da violência escolar na } \\
\text { perspectiva dos diferentes atores de uma comunidade escolar. }\end{array}$ \\
\hline 4 & $\begin{array}{l}\text { Revista Brasileira de E. } \\
\text { Médica }\end{array}$ & $\begin{array}{l}\text { Conhecer e analisar o processo da intersetorialidade no Programa Saúde na Escola (PSE) em } \\
\text { um município da região metropolitana de Pernambuco. }\end{array}$ \\
\hline 5 & $\begin{array}{l}\text { Revista Brasileira de Política } \\
\text { de Saúde }\end{array}$ & $\begin{array}{l}\text { Analisar o processo de cooperação entre os agentes de endemia e a escola em áreas } \\
\text { favoráveis à reprodução do vetor da dengue em domicílios. }\end{array}$ \\
\hline 6 & $\begin{array}{l}\text { Journal of Human Growth } \\
\text { and Development }\end{array}$ & $\begin{array}{l}\text { Identificar e descrever as ações } \\
\text { desenvolvidas pelas Equipes de Saúde da Família (ESF) no Programa Saúde na Escola } \\
\text { (PSE). }\end{array}$ \\
\hline 7 & $\begin{array}{l}\text { International Journal of } \\
\text { Adolescence and Youth }\end{array}$ & $\begin{array}{l}\text { Implementar os Círculos de Cultura como um intervenção em saúde envolvendo } \\
\text { adolescentes, em construção de conhecimento coletivo sobre estratégias para prevenir a } \\
\text { violência. }\end{array}$ \\
\hline
\end{tabular}

Fonte: Autores (2021). 
Tabela 2. Distribuição dos artigos incluídos na revisão integrativa, de acordo com método, amostra, ações e resultados.

\begin{tabular}{|c|c|c|c|c|}
\hline Artigos & Métodos & Amostra & Ações & Resultados \\
\hline 1 & $\begin{array}{l}\text { Estudo } \\
\text { exploratório e } \\
\text { qualitativo }\end{array}$ & Grupos específicos & $\begin{array}{l}\text { Desenvolver ações entre a } \\
\text { saúde e educação } \\
\text { (campanha de vacina, ações } \\
\text { de educação e promoção de } \\
\text { saúde). }\end{array}$ & $\begin{array}{l}\text { Foi possível identificar e analisar } \\
\text { constrangimentos e oportunidades para } \\
\text { implementação de experiências intersetoriais e, } \\
\text { contribuir para reflexão em torno da efetividade } \\
\text { de programas voltados à promoção da saúde. }\end{array}$ \\
\hline 2 & $\begin{array}{l}\text { Estudo descritivo } \\
\text { e qualitativo }\end{array}$ & Grupos específicos & $\begin{array}{l}\text { Intervenções } \\
\text { compartilhadas nas ações do } \\
\text { PSPE (Processos } \\
\text { educativos: ações educação, } \\
\text { saúde e qualidade de vida). } \\
\text { Palestras, oficinas e roda de } \\
\text { conversas. }\end{array}$ & $\begin{array}{l}\text { Os resultados expressaram nível de colaboração } \\
\text { interprofissional no desenvolvimento das ações do } \\
\text { PSPE, são necessários avanços } \\
\text { organizacionais e estruturais que têm impedido ou } \\
\text { limitado o potencial estratégico para promoção da } \\
\text { saúde. }\end{array}$ \\
\hline 3 & $\begin{array}{l}\text { Estudo descritivo } \\
\text { e qualitativo }\end{array}$ & Grupos específicos & $\begin{array}{l}\text { Ações comunitárias e, com } \\
\text { menor intensidade; e ações } \\
\text { individuais, relacionais e } \\
\text { sociais. }\end{array}$ & $\begin{array}{l}\text { Resultou que os procedimentos adotados na } \\
\text { escola, em casos de violência, pelos diferentes } \\
\text { atores, expressaram as dificuldades e as } \\
\text { estratégias relacionadas às experiências e aos } \\
\text { papéis desempenhados. Aponta-se a } \\
\text { potencialidade da construção e o fortalecimento } \\
\text { do diálogo entre os diferentes atores da } \\
\text { comunidade escolar e de uma rede de } \\
\text { enfrentamento intersetorial. }\end{array}$ \\
\hline 4 & $\begin{array}{l}\text { Estudo descritivo } \\
\text { e qualitativo }\end{array}$ & Adolescente & $\begin{array}{l}\text { Ações entre saúde e } \\
\text { educação }- \text { promoção da } \\
\text { saúde. }\end{array}$ & $\begin{array}{l}\text { A pesquisa revelou que o maior dilema é operar } \\
\text { uma política intersetorial, em ambiente cujos } \\
\text { atores possuem agendas setoriais previamente } \\
\text { montadas e sem espaço suficiente para correta } \\
\text { execução da política, o que leva à dificuldade de } \\
\text { conciliar os tempos institucionais dos vários } \\
\text { setores e o comprometimento e envolvimento } \\
\text { setorial, impedindo a sustentabilidade das ações. }\end{array}$ \\
\hline 5 & $\begin{array}{l}\text { Estudo } \\
\text { exploratório, } \\
\text { descritivo, } \\
\text { qualitativo } \\
\text { quantitativo }\end{array}$ & Grupos específicos & $\begin{array}{l}\text { Ações educativas de } \\
\text { controle da dengue. } \\
\text { Visitas domiciliares com } \\
\text { uso do roteiro (checklist). }\end{array}$ & $\begin{array}{l}\text { Observou-se que, em } 83(89,3 \%) \text { casas havia } \\
\text { presença de algum recipiente propício à } \\
\text { reprodução do vetor da dengue. Após o } \\
\text { desenvolvimento de ações educativas, na segunda } \\
\text { e terceira visitas, o número de casas com } \\
\text { criadouros potenciais diminuiu para } 65(70,0 \%) \text { e } \\
63(68,0 \%) \text {, respectivamente, indicando o } \\
\text { potencial dessas atividades para o controle do } \\
\text { vetor da doença. }\end{array}$ \\
\hline 6 & $\begin{array}{l}\text { Estudo descritivo } \\
\text { e qualitativo }\end{array}$ & $\begin{array}{l}\text { Crianças } \\
\text { Adolescentes }\end{array}$ & $\begin{array}{l}\text { Encontro com ações } \\
\text { educativas em prevenção de } \\
\text { acidentes infantis entre } \\
\text { professores e crianças. }\end{array}$ & $\begin{array}{l}\text { As atividades educativas foram avaliadas } \\
\text { positivamente pelos dois segmentos os } \\
\text { participantes e alunos. Os resultados mostraram } \\
\text { ampliação de conhecimentos sobre riscos para } \\
\text { acidentes infantis e formas de prevenção pelas } \\
\text { crianças e respectivo professor. }\end{array}$ \\
\hline 7 & $\begin{array}{l}\text { Estudo descritivo } \\
\text { e qualitativo }\end{array}$ & Adolescentes & $\begin{array}{l}\text { Capacitação de um grupo de } \\
\text { adolescentes. } \\
\text { Ações educativas } \\
\text { sobre violência. }\end{array}$ & $\begin{array}{l}\text { Os resultados mostraram qua a intervenção } \\
\text { capacitou um grupo de adolescentes quanto à } \\
\text { prevenção da violência e permitiu a inclusão de } \\
\text { profissionais de saúde na contexto escolar, de uma } \\
\text { perspectiva interdisciplinar, contribuindo para o } \\
\text { estabelecimento de suporte social e redes de } \\
\text { proteção. }\end{array}$ \\
\hline
\end{tabular}

Fonte: Autores (2021).

\section{Discussão}

\subsection{Estratégias para integralidade nas práticas educativas no cenário escolar}

Os estudos apontaram que as estratégias para integralidade nas práticas educativas desenvolvidas pelos profissionais de saúde no cenário escolar em duas dimensões: a tradicional e a dialógica. 
A primeira dimensão é abordagem tradicional, caracterizada pela concepção de educação como produto, uma vez que os modelos a serem alcançados são pré-estabelecidos (Silva, Martins \& Schall, 2015). Trata-se da transmissão de ideias selecionadas, organizadas logicamente, de forma rígida, centrada no educador, em que o educando escuta as prescrições que lhes são fornecidas.

Esse modelo tradicional de educação adota a supremacia da experiência do educador, cabendo-lhe transmitir o conhecimento e que o educando absorva o conteúdo e reproduza-o com fidelidade. Essa forma de educar ficou conhecida como educação bancária, considerando que o educador deposita o saber, enquanto o educando deveria ser passivo e a educação serviria para moldá-lo ao mundo (Freire, 2010).

A educação tradicional é desenvolvida nas ações educativas de saúde, em que se objetiva capacitar usuários para uma vida saudável, através de metodologias clássicas, como a exposição verbal, foco na repetição e memorização. Envolve, sobretudo, aprendizagem sobre campanhas de saúde, doenças, de como evitá-las, sobre seus efeitos e como restabelecê-los.

Nos estudos selecionados, a dinâmica do ambiente escolar foi frequente nas intervenções em educação e saúde, utilizando-se metodologias tradicionais em maior proporção, oficinas, palestras, campanhas de vacinas e visitas domiciliares (Magalhães, 2015; Silva, Martins \& Schall, 2015).

Sinaliza-se que os processos de educação permanente das equipes de saúde, na maioria das vezes, são realizados por atividades de curta duração, baseadas em práticas isoladas e pontuais, utilizando metodologias centradas nos professores e com ênfase na transmissão de conhecimentos e separando intervenções educacionais e desempenho (Mendes, 2012).

Percebeu-se nos sete estudos que as práticas pedagógicas dos profissionais de saúde, no processo cotidiano de trabalho, especificamente nas ações educativas no ambiente escolar, destes cinco foram com abordagens educacionais tradicionais, realizadas de forma pontual, fragmentada e pouco cooperativa (Magalhães, 2015).

Sob a ótica dos profissionais de saúde e de educação, o trabalho em Educação em Saúde deve ser permanente e não apenas orientações fragmentadas, definidas de modo verticalizado, em que profissionais e comunidade escolar passam a ser sujeito do processo, conduzindo, assim, práticas educativas transformadoras.

A outra dimensão é a educação dialógica, em que se consideram as raízes dos problemas, assumindo como objetivo central a promoção da saúde. Para alcance desse objetivo, pressupõe-se o uso de uma reflexão e análise crítica sobre os aspectos da realidade pessoal e coletiva, visando desenvolver planos de transformação de realidade.

Esse modelo de educação em saúde dialógica caracteriza-se pelo diálogo bidirecional entre as partes envolvidas no processo, rompendo com o modelo tradicional. Além disso, coincide com as diretrizes do atual sistema de saúde, como autonomia e controle social (Mascarenhas, Melo \& Fagundes, 2012; Pallarés, Alves, Aerts \& Câmara, 2016).

Nesse sentido, é imprescindível construir práticas educativas comprometidas com os princípios de cidadania e democracia, e que motive o indivíduo à autonomia e emancipação como sujeito histórico e social, capaz de propor e opinar nas decisões de saúde, evidenciando o compromisso social com a melhoria do estado de saúde dos usuários (Monteiro \& Vieira, 2010).

Nos estudos selecionados, apenas dois utilizaram-se da dimensão dialógica, nos quais os profissionais de saúde usam dos conhecimentos para identificar as necessidades de ações e serviços de saúde, as denominadas práticas em educação e saúde (Kappel, Gontijo, Medeiros \& Monteiro, 2014).

Nesse tipo de abordagem, preconiza-se trabalho com grupos de educação em saúde nos diferentes espaços sociocupacionais, que este trabalho seja realizado por equipe multiprofissional, entretanto, observa-se que os profissionais de saúde têm fragilidade na formação para desempenho de grupos em educação em saúde, utilizando abordagem participativa e dialógica (Pallarés, Alves, Aerts \& Câmara, 2016; Falkenberg, Mendes, Moraes \& Souza, 2014). 
Quanto aos enfoques temáticos, utilizando a educação dialógica, constatou-se que os temas centrais nos grupos de educação e saúde foram promoção de saúde, prevenção de acidentes, violência e qualidade de vida, envolvendo grupos específicos, crianças e adolescentes, na construção de conhecimento coletivo, sobretudo, nas estratégias adotadas para cuidar em saúde (Magalhães, 2015; Silva, Martins \& Schall, 2013; Kappel, Gontijo, Medeiros \& Monteiro, 2014; Falkenberg, Mendes, Moraes \& Souza, 2014).

Os estudos selecionados apontaram a necessidade da construção de estratégias inovadoras de práticas educativas, com tendências pedagógicas crítica e reflexivas em educação e saúde, a interdiciplinariedade, a intersetorialidade, o trabalho em equipe, além da importância do contexto cultural dos escolares.

Por fim, a possibilidade de articular ações preventivas e assistenciais entre setores de saúde e educação envolve possibilidades e limitações. Portanto, infere-se refletir uma nova forma de atender ao indivíduo em sua integralidade, que possa conduzir a uma visão unitária do ser humano, considerado um desafio para as políticas públicas intersetoriais.

\subsection{Desafios e limitações para integralidade das práticas educativas no cenário escolar}

A análise dos estudos demostrou que os profissionais de saúde no processo de trabalho cotidiano nas ações de intervenções em saúde e educação no ambiente escolar buscam a integralidade, embora essas práticas educativas não apresentem claramente a assistência integral aos educandos.

Entende-se que a articulação entre saúde e educação constitui potente ferramenta de educação em saúde, no sentido de fortalecer as ações educativas desenvolvidas pelos profissionais de saúde, as quais são eficazes à assistência integral de saúde.

A integralidade nas práticas educativas no contexto escolar, em particular no PSE, é executada com extrema fragilidade, em decorrência da dificuldade de estratégias de articulação intersetorial e interprofissional, que nem sempre conseguem contar com a colaboração, interação/engajamento entre os profissionais da educação e da saúde, colocam objeção para desenvolverem as atividades, em cumprirem os prazos estipulados, como também em participarem de alguns eventos (Dias, Ribeiro, Silva, Vasconcelos \& Machado, 2016).

Percebeu-se que os momentos de encontro dos profissionais do PSE eram para discussões de questões de caráter pontual e específicos, além das atividades pouco colaborativas entre os profissionais de saúde e de educação e, os espaços disponíveis nas escolas eram restritos para discussões de caráter campanhista e projetos pontuais e pouco abrangentes.

Nos estudos, evidenciou-se que ações de educação em saúde são atribuições dos profissionais de saúde, entretanto, observou-se que os profissionais não estavam preparados para o desenvolvimento dessas atividades, ademais, essas ações apoiavam-se na perspectiva da transmissão de um saber especializado, técnico e hegemônico sobre o saber popular.

Nesse sentido, as ações em saúde e educação no âmbito escolar são desenvolvidas de forma pontuais e focalizadas para grupos mais específicos, no entanto, ações isoladas e desarticuladas, dificilmente são capazes de romper com práticas educativas tradicionais/verticalizas, a fim de gerar concepções educacionais democráticas e emancipatórias (Magalhães, 2015).

É perceptível que os processos de desenvolvimento das competências dos profissionais desses estudos podem ser potencializados para efetivação e concretização do nível de colaboração interprofissional, articulação de setores e práticas críticas e reflexivas, constituindo, ainda, um desafio a ser superado.

Outro empecilho é a incompatibilização de agendas profissionais para planejamentos das ações em conjunto entre saúde e educação, como também fragilidade de capacitação profissional e habilidades entre os setores de educação e saúde, dificultando o desenvolvimento de uma cultura política intersetorial, além de carências de estudos recentes na área (Falkenberg, Mendes, Moraes \& Souza, 2014).

Outro ponto igualmente importante é o estabelecimento das parcerias, que não devem limitar-se à rede de saúde e de educação, mas articular outras redes para execução das práticas. É essencial o apoio continuado da equipe de coordenação do 
Estratégia Saúde da Família-ESF e Programa Saúde na Escola-PSE, para facilitar ações de Educação em Saúde, fortalecendo as alianças, disponibilizando material educativo e recursos materiais.

Foram identificados nos estudos algumas limitações relacionais no cenário escolar, baixa participação dos alunos e dos pais nas atividades de Educação em Saúde, pouco envolvimento da família no acompanhamento e monitoramento das atividades dos escolares (Falkenberg, Mendes, Moraes \& Souza, 2014).

Observou-se baixa adesão dos alunos e pais no desenvolvimento das atividades em saúde, assim, apontam a necessidade de potencializar a construção e o fortalecimento do diálogo entre os diferentes atores da comunidade escolar, a fim de transformar a relação família-escola, no sentido de que ela possa ser parceira nos processos de socialização e aprendizagens significativas.

Para análise da integralidade nas práticas educativas no cenário escolar, foi imprescindível identificar no campo da saúde e da educação os desafios e as limitações para operacionalização das ações intersetoriais. Tais limitações caracterizam-se como ações isoladas, fragmentadas, pontuais, baixo nível de colaboração e participação, apresentam fragilidade na capacitação dos profissionais e escassez de estudos recentes.

Evidencia-se a necessidade de adotar processos educativas participativos, inovadores e emancipatórios, sendo indispensável a capacitação de profissionais para transformação das práticas de saúde.

Aponta-se a importância dos estudos de revisão e atualização acerca da integralidade nas práticas educativas, pois merece atenção a reflexão aprofundada e crítica da integralidade das ações de educação em saúde no cenário escolar, ainda pouco discutido na literatura, mas de prevalência significativa e relevância no que se refere à construção de uma cultura de intersetorialidade.

\section{Considerações Finais}

Os estudos analisados evidenciaram que a integralidade das práticas educativas desenvolvidos pelos profissionais de saúde junto aos escolares requer estratégias inovadoras, transformadoras e práticas críticas e reflexivas.

Para a integralidade dessas práticas educativas, são necessários dispositivos de compartilhamento de procedimentos, responsabilização e estratégias de enfrentamento pelos profissionais de saúde, capaz de fornecer oportunidades de respostas ao conjunto das demandas de saúde dos escolares.

Aponta-se para organização dos serviços a construção de uma agenda única, planejamento das ações em educação e saúde entre gestores e profissionais envolvidos nas políticas setoriais, em que permitem oferecer, para além das ações demandas pelos escolares, intervenções voltadas para prevenção, impactando no processo de ensino-aprendizagem em todas as esferas da vida, inclusive, na saúde.

É essencial o engajamento dos profissionais na construção de experiências e práticas educativas pautadas pela intregalidade capaz de apreender as necessisdades de saúde e gerar novos conhecimentos, que possibilitem orientar os processos formativos com práticas inovadoras, voltadas à prevenção e qualificação de cuidados de saúde comprometidos com autonomia e bem-estar social de escolares.

Espera-se que os conhecimentos revelados nos estudos selecionados possam ampliar as possibilidades de reflexão sobre a integralidade das práticas educativas nos serviços de saúde, no contexto escolar, e que as formas de organizar as ações propiciem abordagem integral e integradora, em uma perpectiva ampliada de promoção de saúde. 


\section{Referências}

Bardin, L. (2011). Análise de conteúdo. Edições 70.

Dias, M. S. A. V., Ribeiro, F. M. B., Silva, L. C. C., Vasconcelos, M. I. O., \& Machado, M. F. A. S. (2016). Colaboração interprofissional no Projeto Saúde e Prevenção na Escola. Ciênc Saúde Coletiva, 21(6), 1789-98.

Falkenberg, M. B., Mendes, T. P. L., Moraes, E. P., \& Souza, E. M. (2014). Educação em saúde e educação na saúde: conceitos e implicações para a saúde coletiva. Ciênc Saúde Coletiva, 19(3), 847-852.

Feuerwerker, L. C. M. (1998). Mudanças na educação médica e residência médica no Brasil. Interface-Comun Saúde Educ, 2(3), 51-71.

Fracolli, L. A., Zoboli, E. L. P., Granja, G. F., \& Ermel, R. C. (2011). Conceito e prática da integralidade na Atenção Básica: a percepção das enfermeiras. Rev Esc Enferm USP, 45(5), 1135-1141.

Freire, P. (2002). Pedagogia do oprimido. Paz e Terra.

Freire, P. (2005). Freire P. Pedagogia da autonomia: saberes necessários à prática educativa. 31aㅡ ed. Rio de Janeiro: Paz e terra.

Freire, P. (2010). Pedagogia da autonomia. Paz e Terra.

Hermann, C. P., Head, B. A., Black, K., \& Singleton, K. (2016). Preparing nursing studants for interproffissional practice: the interdiciplinary curricullum for oncolgy. J Prof Nurs, 32(1), 62-71.

Kantor, S. A. (2010). Pedagogical change in nursing education: one instructor's experience. J Nurs Educ, 49(7), 414-417.

Kappel, V. B., Gontijo, D. T., Medeiros, M., \& Monteiro, E. M. L. M. (2014). Enfrentamento da violência no ambiente escolar na perspectiva dos diferentes atores. Interface (Botucatu), 18(51), 723-725.

Lima, M. M., Reibnitz, K. S., Prado, M. L., \& Kloh, D. (2013). Integralidade como princípio pedagógico na formação do enfermeiro. Texto Contexto Enferm, 22(1), 106-113.

Magalhães, R. (2015). Constrangimentos e oportunidades para a implementação de iniciativas intersetoriais de promoção da saúde: um estudo de caso. Cad Saúde Pública, 31(7), 1427-1436.

Mascarenhas, N. B., Melo, C. M. M., \& Fagundes, N. C. (2012). Produção do conhecimento sobre promoção da saúde e prática da enfermeira na Atenção Primária. Rev Bras Enferm, 65(6), 991-999.

Mattos, R. A. (2009). Os sentidos da integralidade: algumas reflexões acerca dos valores que merecem ser definidos. In: Pinheiro, R., \& Mattos, R.A. Os sentidos da integralidade na atenção e no cuidado à saúde (pp. 11-15). CEPESC, IMS/URJ.

Mendes, E. V. (1996). Uma agenda para a Saúde. Ed. Hucitec.

Mendes, E. V. (2012). O cuidado das condições crônicas na atenção primária à saúde: o imperativo da consolidação da estratégia da saúde da família. Brasília: Organização Pan-Americana de Saúde; Conselho Nacional de Secretários de Saúde.

Monteiro, E. M. L. M., \& Vieira, N. F. C. (2010). Educação em saúde a partir de círculos de cultura. Rev Bras Enferm, 63(3), 397-403.

Pallarés, E. C., Alves, G. G., Aerts, D., \& Câmara, S. (2016). Atenção primária em saúde: a adequação ao modelo da vigilância da saúde em município do sul do Brasil. Aletheia, 49(2), 89-109.

Pinheiro, R. (2008). Integralide como princípio de saúde. Dicionário educação do profissional de saúde/Isabel Brasil Pereira e Júlio César França Lima. Fundação Oswaldo Cruz. Escola Politécnica de Saúde Joaquim Venâncio. Rio de Janeiro: EPSJV. (2), 255-258.

Silva, P. C., Martins, A. M., \& Schall, V. T. (2013). Cooperação entre agentes de endemias e escolas na identificação e controle da dengue. Rev Bras Prom Saúde, 26(3), 404-411.

Thiollent, M. (2011). Metodologia da pesquisa-ação. Cortez.

Westin, L., Sundler, A. J., \& Berglund, M. (2015). Students' experiences of learning in relation to didactic strategies during the first year of a nursing programme: a qualitative study. BMC Med Educ, 15(49), 1-8. 